\title{
First Antiretroviral Therapy Changes in People Living with HIV in Senegal: Incidence, Causes and Predictive Factors
}

Assane Diouf ${ }^{1,2,3}$, Tracie Joyner Youbong1,4, Fatou Lama Dieye ${ }^{5}$, Viviane Marie Pierre Cisse-Diallo1, Khardiata Diallo-Mbaye ${ }^{1}$, Moustapha Diop1, Maryvonne Maynart ${ }^{1,6}$, Cheikh Tacko Diop ${ }^{7}$ and Moussa Seydi ${ }^{1}$

${ }^{1}$ Department of Infectious Diseases, Regional Research and Training Center on HIV and Associated Diseases, Fann's University Hospital Center, Dakar, Senegal

${ }^{2}$ School of Public Health, Department of Social and Preventive Medicine, Université de Montréal, Montreal, Canada

${ }^{3}$ Sainte-Justine University Hospital Research Center, Montreal, Canada

${ }^{4}$ Principal Hospital of Dakar, Dakar, Senegal

${ }^{5}$ Division of Fight against aids (DLSI), Dakar, Senegal

${ }^{6}$ National Alliance of Communities for Health, Dakar, Senegal

${ }^{7}$ Fann University Hospital Center, Dakar, Senegal

\section{Abstract}

Introduction: In resource-limited countries, the number of available antiretroviral (ARV) drugs is relatively limited. Hence, caregivers face some caution and constraints in the changes of ARV treatment (ART) in people living with HIV (PLHIV). Our objective was to calculate the incidence, to describe the main causes and to identify the predictive factors of the first change of ARV treatment in Senegal.

Methods: We conducted a retrospective cohort study on $331 \mathrm{HIV}$ infected patients who initiated ART in 20092011 and followed until March 2012. The incidence was estimated using Kaplan-Meier method. The causes have been grouped into five categories. The identification of predictive factors was done using a Cox proportional hazards model.

Results: At inclusion, mean age, IMC and CD4 cell count were 41 years (interquartile range $(I Q R)=35-48), 18 \mathrm{~kg} /$

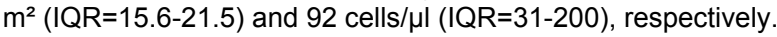

After an average ART duration of 11.4 months, 65 patients had experienced at least one treatment change resulting in an overall incidence rate of $10.5 / 100$ person-years $(95 \% \mathrm{Cl}=8.4-12.6)$. ARV drugs intolerance was the main cause of change in treatment (41/65) followed by therapeutic failures (5 cases) and pregnancy (three cases). The independent predictors of first ARV treatment change were female sex (hazard ratio $(H R)=1.85$ : IC 95\%=1.07-3.19), underweight $(H R=2.20, I C 95 \%=1.24-3.88)$ and HIV-1 or HIV-dual infection (HR=3.57, IC 95\%=1.11-11.46).

Conclusion: In this cohort, the incidence of the first ARV treatment change was low. It was more frequent in women, underweight patients and HIV-1 infected patients. The main cause was ARV intolerance. A better pretherapeutic evaluation, the availability of ARVs compatible with pregnancy and anti-tuberculosis treatment appear to be relevant in this population.

Keywords: HIV; Anti-retroviral therapy; Substitution treatment

\section{Introduction}

In December 2016, 19.5 million people were receiving antiretroviral therapy (ART) worldwide [1]: an unprecedented number that resulted from increasing access to ART in resource-limited countries (RLC).

Despite these advances, HIV is still managed at two speeds: at least 25 ARV drugs from six therapeutic classes have been approved and are available in rich countries while poor countries have to cope with essentially a dozen of ARV drugs of the first three therapeutic classes.

More specifically, in Senegal, the number of people living with HIV (PLHIV) on ART was 18375 in December 2015 [2]. It was 13716 in December 2013 [3] and eleven ARVs were available there at that time. These were seven nucleoside reverse transcriptase inhibitors (NRTIs): Zidovudine (AZT), Lamivudine (3TC), Emtricitabine (FTC), Didanosine (ddI), Tenofovir (TDF), Abacavir (ABC); Stavudine (d4T); two non-nucleoside reverse transcriptase inhibitors (NNRTIs): Nevirapine (NVP), Efavirenz (EFV) and two protease inhibitors (PI): ritonavir-boosted Lopinavir (LTV/r) and ritonavir-boosted Atazanavir $(\mathrm{ATV} / \mathrm{r})$. First-line therapeutic combinations where in accordance with 2013 WHO guidelines [4]. Fixed dose combinations were preferred. Those available were: AZT+3TC, TDF+3TC, TDF+FTC, $\mathrm{TDF}+\mathrm{FTC}+\mathrm{EFV}$. This limited number of ARVs imposed constraints on the initiation of ART and especially on the management of ART changes in PLHIV. The objective of this study was to assess the overall incidence of the first ART change in this population and their causes; as well as the predictive factors for the first ART change.

\section{Methods}

We conducted a retrospective cohort study on the population of PLHIV followed at the Department of Infectious Diseases/Regional Research and Training Center on HIV and Associated Diseases, Fann's University Hospital Center, Dakar, Senegal(SMIT/CRCF). This study included PLHIV who had started ART between January 1, 2009 and December 31,2011. The first-line ART eligibility criteria were consistent with the 2010 WHO recommendations for ART initiation [5]. After ART initiation, follow-up visits were carried out at D15, M1, M2, M3,

*Corresponding author: Dr. Assane DIOUF, Department of Social and Preventive Medicine, Université de Montréal, CHU Sainte-Justine Research Center, 3175 Côte Ste-Catherine, Room B.17.002, Montreal, Qc, Canada, H3T 1C5; Tel: 514-345-4931 Ext. 7152; Fax : 514-345-4801; E-mail: a.diouf@umontreal.ca

Received July 05, 2017; Accepted July 11, 2017; Published July 18, 2017

Citation: Diouf A, Youbong TJ, Dieye FL, Ciss VMP, Cisse-Diallo VMP, et al. (2017) First Antiretroviral Therapy Changes in People Living with HIV in Senegal: Incidence, Causes and Predictive Factors. J AIDS Clin Res 8: 709. doi: 10.4172/2155-6113.1000709

Copyright: () 2017 Diouf A, et al. This is an open-access article distributed unde the terms of the Creative Commons Attribution License, which permits unrestricted use, distribution, and reproduction in any medium, provided the original author and source are credited. 
Citation: Diouf A, Youbong TJ, Dieye FL, Ciss VMP, Cisse-Diallo VMP, et al. (2017) First Antiretroviral Therapy Changes in People Living with HIV in Senegal: Incidence, Causes and Predictive Factors. J AIDS Clin Res 8: 709. doi: 10.4172/2155-6113.1000709

Page 2 of 5

M6 and then every three months. Routine clinical and biological data (age, sex, occupation, marital status, weight, height, clinical stage, HIV serotype, cell blood count, transaminases, serum creatinine, CD4 cell count, plasma viral load) were collected from the medical records of the PLHIV. Data on changes in ART and their causes were collected from medical records and prescriptions classified at the pharmacy.

The data were entered on an Excel database and analyzed using the Stata software version 14 . The event of interest was the first change in ART regardless its cause and the random variable studied was the exposure time to the first ART that was defined as the period between the initiation of the first line ART and the date of the first ART change (for any reason) for patients who had a change in treatment prior to March 16, 2012. For patients who didn't experience an ART change, the data were censored at the date of death or date of last visit. The incidence was estimated using the Kaplan-Meier method. The causes of the first ART changes were grouped into different categories: intolerance, therapeutic failure, ARV stock out, intercurrent disease, desire for pregnancy or ongoing pregnancy. For each category, the overall incidence was measured; as well as the incidence during the first semester of ART and beyond. The identification of predictive factors of change in treatment (any cause) was performed using a Cox proportional hazard model with fixed co-variables: age, sex, body mass index (BMI), WHO clinical stage, HIV serotype, hemoglobin level, CD4 cell count, transaminases, creatinine.

\section{Results}

\section{Study population}

At ART initiation, the patients' ages ranged from 16 years to 70 years old (median $=41$ years). The majority of these patients $(61 \%, 95 \%$ $\mathrm{CI}=55.6-66.2)$ were female. An important proportion was infected with HIV-1 (283=85.5\%; 95\% CI=81.2-88.9). Thirty-four were infected with HIV-2 (34=10.3\%, 95\% CI=7.3-14.0), while fourteen $(4.2 \%$; $95 \%$ $\mathrm{CI}=7.3-14.0$ ) were dually-infected with HIV-1 and HIV-2 (HIV-D). Almost $80 \%$ of these patients had advanced or severe symptoms, including $39.7 \%(95 \% \mathrm{CI}=34.2-45.4)$ at WHO stage 4 . More than half of the patients had a BMI $<18.5 \mathrm{~kg} / \mathrm{m}^{2}$ and $34.8 \%(95 \% \mathrm{CI}=29.7-40.3)$ had less than $50 \mathrm{CD} 4 / \mu \mathrm{l}$ (Table 1). The delay between the knowledge of HIV positive status and the first visit in the clinic was specified in 218 patients, ranging from 0 to 2050 days with an average of 38 days (standard deviation $(\mathrm{SD})=148$ ) The average time between the first visit and ART initiation was 31 days $(\mathrm{SD}=163)$.

The different first line ART regimens are presented in Table 2. Five patients were receiving 3 NRTIs while two other patients (one infected with HIV-2 and one dually infected) were receiving two NRTIs and one NNRTI; although HIV-2 is naturally resistant to NNRTIs.

At the endpoint date, the average follow-up duration was 11.4 months ( $\mathrm{SD}=10.8$ months). A total of $226(68.7 \%)$ patients were still being followed, 23 (7\%) were transferred, 37 (11.2\%) were reported lost to follow-up and $43(13.1 \%)$ were deceased.

\section{Overall incidence of first ART change}

After an average duration of ART of 11.4 months, 65 patients had at least one change in treatment: $19.6 \%$ of the population $(95 \%$ $\mathrm{CI}=15.4-23.9)$. During the 38 month follow-up, the overall incidence rate was $10.5 / 100$ person-years (PY) (95\% CI=8.4-12.6). The incidence rate decreased with follow-up duration. It was 30/100 PY during the first semester $(95 \% \mathrm{CI}=21.4-38.6)$ and $8.7 / 100$ PY beyond $(95 \%$ $\mathrm{CI}=5.7-11.6) ; \mathrm{P}<0.001$. In the first year and the second year of follow- up, incidence rates were 22.1/100 PY (95\% CI=16.8-27.3) and 10.9/100 PY (95\% CI=4.6-17.2), respectively.

The cumulative incidence was $22.8 \%$ after one year of treatment (95\% CI=18.2-27.3), 34.8\% after two years $(95 \% \mathrm{CI}=29.7-39.9)$ and $38.7 \%$ after three years $(95 \% \mathrm{CI}=33.5-44.0)$. The increase was more significant during the first months of follow-up (Figure 1).

\section{Causes of ART changes}

In the population studied and during the follow-up period, 65 incident changes in ART were observed. The majority (41) was attributed to intolerance to ARVs, 32 of which occurred during the first

\begin{tabular}{|c|c|c|}
\hline Characteristics & $\mathbf{N}$ & Median (IQR $\left.{ }^{a}\right)$ or $\%$ \\
\hline Age (years) & 329 & $41(35-48)$ \\
\hline$<45$ & 208 & 63.2 \\
\hline Sex & 331 & \\
\hline Male & 129 & 39.0 \\
\hline BMI $\left(\mathbf{k g} / \mathbf{m}^{2}\right)$ & 238 & $18(15.6-21.5)$ \\
\hline$<18.5$ & 126 & 52.9 \\
\hline $18.5 \leq \mathrm{IMC}<25$ & 86 & 36.1 \\
\hline$\geq 25$ & 26 & 10.9 \\
\hline HIV serotype & 331 & \\
\hline HIV-1 & 283 & 85.5 \\
\hline HIV-2 & 34 & 10.3 \\
\hline HIV-Dual & 14 & 4.2 \\
\hline WHO clinical stage & 295 & \\
\hline Stage 1 or 2 & 63 & 21.4 \\
\hline Stage 3 or 4 & 232 & 78.6 \\
\hline Haemoglobin level (g/dL) & 299 & $10(8.2-11.4)$ \\
\hline$\leq 11$ & 210 & 70.2 \\
\hline Creatinin level (mg/L) & 269 & $9.1(7-11)$ \\
\hline$>15$ & 15 & 5.6 \\
\hline ALAT (IU/L) & 272 & $24(16-39)$ \\
\hline$>100$ & 7 & 2.6 \\
\hline CD4 cell count (cells/ $/ \mathrm{L})$ & 313 & $92(31-200)$ \\
\hline$<200$ & 234 & 74.8 \\
\hline
\end{tabular}

anterquartile range

Table 1: Baseline characteristics of the study population.

\begin{tabular}{|c|c|c|c|c|c|}
\hline \multirow[b]{2}{*}{ ART regimens } & \multicolumn{3}{|c|}{ HIV serotype } & \multirow[b]{2}{*}{$\mathbf{N}$} & \multirow[b]{2}{*}{$\%$} \\
\hline & HIV-1 & HIV-2 & HIV-Dual & & \\
\hline$A Z T+X T C+E F V$ & 111 & 1 & 1 & 113 & 34.1 \\
\hline$A Z T+X T C+N V P$ & 53 & 0 & 0 & 53 & 16.0 \\
\hline$T D F+X T C+E F V$ & 77 & 0 & 0 & 77 & 23.3 \\
\hline$T D F+X T C+N V P$ & 26 & 0 & 0 & 26 & 7.9 \\
\hline$D 4 T+X T C+E F V$ & 5 & 0 & 0 & 5 & 1.5 \\
\hline$D 4 T+X T C+N V P$ & 7 & 0 & 0 & 7 & 2.1 \\
\hline$A Z T+X T C+L P V / r$ & 2 & 23 & 9 & 34 & 10.3 \\
\hline$T D F+X T C+L P V / r$ & 0 & 7 & 1 & 8 & 2.4 \\
\hline$D 4 T+X T C+L P V / r$ & 0 & 2 & 0 & 2 & 0.6 \\
\hline$A Z T+X T C+A B C$ & 0 & 1 & 2 & 3 & 0.9 \\
\hline$A Z T+X T C+T D F$ & 1 & 0 & 0 & 1 & 0.3 \\
\hline$T D F+X T C+A B C$ & 0 & 0 & 1 & 1 & 0.3 \\
\hline$A B C+X T C+E F V$ & 1 & 0 & 0 & 1 & 0.3 \\
\hline Total & 283 & 34 & 14 & 331 & 100 \\
\hline
\end{tabular}

${ }^{1}=3 \mathrm{TC}$ or FTC

Table 2: First line ART regimens by HIV serotype. 


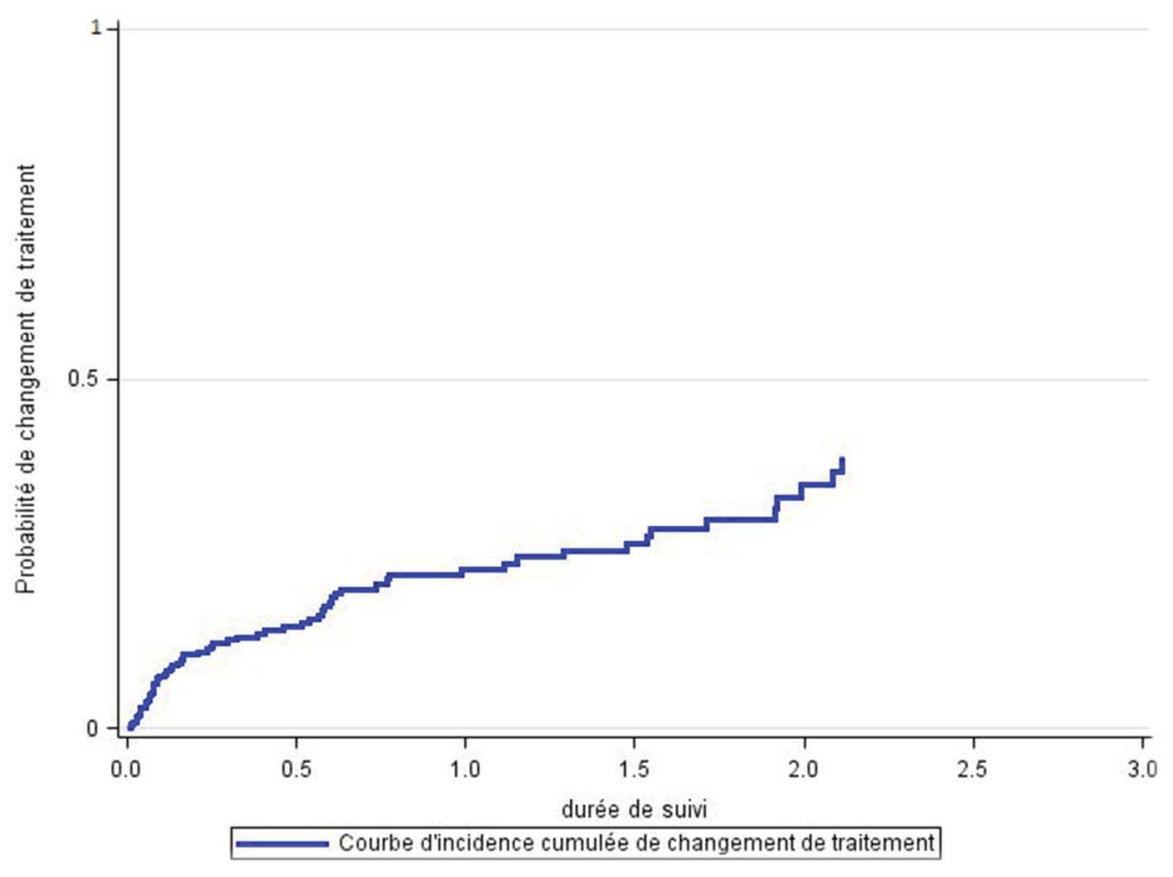

Figure 1: Cumulative incidence of first ART change.

semester and 9 after six months of follow-up. Five incident changes were attributed to therapeutic failures and they were all recorded after the first semester of follow-up. Only one change by ARV stock out was notified after six months. The other most frequent causes were the discovery of an ongoing pregnancy or the desire for pregnancy (three cases), the initiation of an anti-tuberculosis treatment (two cases) and the discovery of a positive HBs antigen (two cases). The most frequently discontinued ARV drugs were AZT, d4T, NVP and EFV.

The incidence of changes in treatment by ARV intolerance was 24.4/100 PY (95\% CI=16.5-32.3) during the first semester of followup and 3.5/100 PY (95\% CI=1.3-5.7) after the first semester; $\mathrm{p}<0.05$. Changes related to therapeutic failure did not occur during the first semester and the incidence was 2.3/100 PY after six months of treatment $(95 \% \mathrm{CI}=0.3-4.2)$.

\section{Predictive factors of the first ART change}

\section{The Cox regression models are presented in Table 3.}

In univariable analysis and, at a $20 \%$ significance level, the risk of change in treatment was higher in women, HIV-1 and HIV-D infected patients (versus HIV-2), underweight patients, those with a low CD4 cell count $(<200 / \mu \mathrm{l})$ and those with a low hemoglobin level $(<11 \mathrm{~g} / \mathrm{dl})$.

After adjustment on eventual confounders, the independent predictors of the first ART change were female sex, underweight, HIV1 and HIV-D infection. Female patients had a risk of ART change nearly twice higher than that of male patients $(\mathrm{HR}=1.85,95 \% \mathrm{CI}=1.07$ 3.19). Underweight patients were more than twice at risk for ART change than those with a BMI $\geq 18.5 \mathrm{~kg} / \mathrm{m}^{2}(\mathrm{HR}=2.20,95 \% \mathrm{CI}=1.24$ 3.88). Compared with HIV-2 infected patients, HIV-1 and HIV-Dinfected patients were at much greater risk of ART change $(\mathrm{HR}=3.57$, $95 \% \mathrm{CI}=1.11-11.46)$.

\section{Discussion}

After 38 months of follow-up, the overall incidence of ART change was $10.5 / 100 \mathrm{P}-\mathrm{Y}$. These changes were mainly attributed to poor tolerance of ARVs, therapeutic failures, desire of or ongoing pregnancy, initiation of anti-tuberculosis treatment, discovery of a positive HBs antigen or, more rarely, ARV stock out. Independent risk factors for the first ART change in this population were female sex, underweight, HIV-1 and HIV-D infections (comparing HIV-2 infection).

Our study took place at the SMIT/CRCF, which is a reference center that is supposed to ensure quality monitoring of PLHIV with good record keeping. It looked at the occurrence of changes in ART. The advantage of a longitudinal study is that it is possible to identify risk factors or predictive factors that underlie these changes after ARV initiation. The data of our study were collected through two sources: medical records were confronted with prescriptions in order to have comprehensive data on treatment changes in our cohort.

Our study was retrospective and, as a result, it has limitations on accessibility and completeness of medical records: therefore, important co-variables such as adherence, preparation of patients for ART were not included in our analysis. Neither was the viral load included, as this variable was only available for a very small proportion of patients at inclusion. The duration of follow-up was relatively short and the number of events low after the first semester.

The characteristics of our cohort (advanced age, low BMI, advanced clinical stage and low CD4 cell count) suggest a deep immunosuppression. Similar characteristics were observed in most of the cohorts studied in the RLC [6,7].

The incidence rates previously reported in West Africa are higher than those observed in our cohort. In Côte d'Ivoire, an overall treatment change incidence of 20.7/100 PY has been reported for a median duration of 16.9 months [8]. In Mali, the incidence rate of ART changes was 16.2/100 PY for a median duration of 15 months [9]. Similarly, a study in Kenya, found an incidence of 18.6/100 PY for a median duration of 10.7 months [10]. 


\begin{tabular}{|c|c|c|}
\hline Characteristics & $\begin{array}{l}\text { Univariable analysis } \\
\text { Hazard Ratio }(95 \% \mathrm{CI})\end{array}$ & $\begin{array}{l}\text { Multivariable analysis } \\
\text { Hazard Ratio }(95 \% \mathrm{Cl})\end{array}$ \\
\hline Age (years) & $0.99(0.97-1.02)$ & - \\
\hline Female sex ${ }^{\alpha}$ & $1.85(1.08-3.19)$ & $1.85(1.07-3.19)$ \\
\hline HIV-1 or HIV-D ${ }^{\beta}$ & $2.80(0.88-8.94)$ & $3.57(1.11-11.46)$ \\
\hline WHO stage 3 or $4^{r}$ & $1.22(0.63-2.35)$ & - \\
\hline BMI $\left(\mathrm{kg} / \mathrm{m}^{2}\right) \leq 18,5^{\circ}$ & $2.06(1.17-3.62)$ & $2.20(1.24-3.88)$ \\
\hline CD4 cell count $\leq 200 / \mu \mathrm{L}$ & $1.77(0.94-3.32)$ & $1.63(0.86-3.29)$ \\
\hline Haemoglobin level (g/dL) & $0.91(0.93-1.26)$ & $0.99(0.88-1.14)$ \\
\hline Creatinin level (mg/L) & $0.99(0.95-1.13)$ & - \\
\hline Transaminases (IU/L) & $0.99(0.99-1.01)$ & - \\
\hline
\end{tabular}

${ }^{a}$ reference $=$ male sex, ${ }^{\beta}$ reference=HIV-2, ${ }^{\vee}$ reference $=\mathrm{WHO}$ stage $1 / 2,{ }^{\circ}$ reference $=\mathrm{BMI}>18.5 \mathrm{~kg} / \mathrm{m}^{2}$

Table 3: Cox models identifying the predictive factors for the first ART change.

The lower incidence in our cohort could be explained by the use of less toxic first-line regimens such as TDF than in previous studies. In our study, nearly $40 \%$ of patients were receiving TDF as first line treatment compared to $4.2 \%$ who received $\mathrm{d} 4 \mathrm{~T}$. The first-line regimens used in the above studies contained little or no TDF. They were mainly based on AZT, d4T and NVP. Given the toxicity profiles of these different ARVs and the role of ARV side effects in treatment changes, the lower incidence observed in our cohort seems relevant. Another explanation could be the empirical application by clinicians of a strategy of "saving ARV molecules" but there is no evidence to suggest a different application in Senegal.

In the literature, ARV side effects are the main cause of the changes in treatment [11-15]. These results are consistent with those found in our study. Similarly, the causes of change in treatment observed in our cohort are in accordance with those reported in Côte d'Ivoire [8]: ARV intolerance was the main cause of treatment changes with an incidence rate of 12.4/100 PY and over one third of these changes were due to pregnancy and tuberculosis.

In Mali, the study rather focused on line-of-treatment changes and reported a second-line incidence of 3.3/100 PY [9]: a low incidence consistent with the one of our study and other data from developing countries $[5,10,16-20]$. The mechanisms of "economy of molecules" can be put forward as an explanation but also the routine nonavailability of the viral load. Indeed, the diagnosis of therapeutic failure was mainly based on immunological or even clinical criteria which can lead to an underestimation of the incidence. As a result, the revised WHO guidelines now recommend the use of the routine viral load as the best tool for the monitoring of ART [4].

A single change in treatment by stock out was noted in our study. In Côte d'Ivoire, stock outs were the cause of ART changes in 1-6\% of cases [8]. The improvement of the supply system, the better accessibility to ARVs and the development of emergency mechanisms explain the fact that stock outs very rarely cause a change in treatment.

The discovery of a positive HBs antigen resulted in an ART change in 2 cases. This finding is consistent with the results of Anlay et al. [7] and Njuguna et al. [21] who found 1 and 8 cases of HBs antigen positivity, respectively, which resulted in ART changes [7,21]. It was only in 2013 that the WHO has recommended the use of TDF+XTC+EFV (HIV1) or TDF+XTC+LPV/R (HIV-2 and HIV-1+2) as first line ART, explaining the change in treatment in all of these studies [16].

Our study found that the female sex, underweight and HIV serotype were predictive factors for ART change. Studies that addressed risk factors for ART change had significant methodological differences from our own: they were specifically concerned with intolerance of certain ARVs $[8,10,22]$, changes in therapeutic lines [9] or delays in ART changes [23-25]. In Mali, the risk factors for line change were: a change in previous ART, low CD4 cell counts, advanced age and triple therapy with NNRTI in HIV-2 infected patients [9]. In this study, some variables such as HBV serology, HIV-D infection were not taken into account although they are potential confounders.

In India, Chandy et al. [23] used a model based on the Generalized Estimation Equations (GEE) with the change delay as an independent variable. They also considered behavioral data such as stigma, depression, adherence and quality of life. Associated factors were side effects and low CD4 count. Whereas Slama et al. [25] found as associated factors nonsuppression of the viral load, non-adherence to ART and side effects.

It is nevertheless recognized that in West Africa, female PLHIV are more adherent to treatment and follow-up, and therefore with a greater likelihood of benefiting from a change in ART. Malnutrition is often associated with metabolic disorders that may be contra-indications of ARVs or factors contributing to their toxicity; the absence of systematic blood-biochemical evaluation may explain the greater frequency of ART changes in this case. The therapeutic arsenal is more limited for patients infected with HIV-2 which is naturally resistant to NNRTIs. There are fewer opportunities for change in this population; resulting in lower frequency.

ART changes are more frequent in high-income countries [26]. This reflects the enormous differences in the management of PLHIVs vis-àvis poorer countries: a much wider and diversified therapeutic arsenal and routine availability of viral load and genotyping tests provide more latitude and comfort in treatment changes in rich countries.

\section{Conclusion}

Our study looked at the first ART change in a resource-constrained context characterized by a limited therapeutic arsenal and patients at an advanced disease stage. The incidence was low here with the main reason being ARV intolerance.

A better pre-therapeutic evaluation of patients, earlier ART initiation, a more diversified therapeutic arsenal and the availability of ARV drugs compatible with pregnancy and tuberculosis treatment should allow better management of initial ART changes in sub-Saharan Africa.

\section{Acknowledgement}

The authors acknowledge all the people living with HIV who consent to participate to this study, the social workers of SMIT/CRCF (Mariane Ndiaye Berthé Catherine Fall Sané, Absa Ba and Khady Gassama), the pharmacists of CRCF (Pr Bara Ndiaye, Dr. Mama Basty Koita-Fall, Dr. Mamadou Ndoye) and the medical secretary of the SMIT/CRCF (Mrs Coumba Guèye Cissé). 
Citation: Diouf A, Youbong TJ, Dieye FL, Ciss VMP, Cisse-Diallo VMP, et al. (2017) First Antiretroviral Therapy Changes in People Living with HIV in Senegal: Incidence, Causes and Predictive Factors. J AIDS Clin Res 8: 709. doi: 10.4172/2155-6113.1000709

\section{References}

1. Joint United Nations Programme on HIVIAIDS (UNAIDS). Ending AIDS Progress towards the 90-90-90 targets. UNAIDS, Geneva 2017

2. Rapport annuel (2016) Conseil National de Lutte contre le Sida (CNLS) République du Sénégal, République du Sénégal.

3. République du Sénégal, Conseil National de Lutte contre le Sida (CNLS), Programme Commun des Nations Unies sur le VIH/sida (ONUSIDA) (2014) Rapport de situation sur la riposte nationale à l'épidémie de $\mathrm{VIH} / \mathrm{sida}$, Sénégal 2012-2013. Mars.

4. World Health Organization (2013) Consolidated guidelines on the use of antiretroviral drugs for treating and preventing HIV infection: Recommendations for a Public Health Approach. World Health Organization, Geneva.

5. Organisation Mondiale de la Santé (2010) Traitement antirétroviral de l'infection à VIH chez l'adulte et l'adolescent. Recommandations pour une approche de santé publique. Mise à jour, OMS

6. ART-LINC of leDEA Study Group, Keiser O, Tweya H, Boulle A, Braitstein P, et al. (2009) Switching to second-line antiretroviral therapy in resource-limited settings: Comparison of programmes with and without viral load monitoring. AIDS 23: 1867-1874.

7. Anlay DZ, Alemayehu ZA, Dachew BA (2016) Rate of initial highly active antiretroviral therapy regimen change and its predictors among adult HIV patients at University of Gondar Referral Hospital, Northwest Ethiopia: A retrospective follow up study. AIDS Res Ther 13: 10.

8. Messou E, Anglaret X, Duvignac J, Konan-N'dri E, Komena E, et al. (2010) Antiretroviral treatment changes in adults from Côte d'Ivoire: the roles of tuberculosis and pregnancy. AIDS 24: 93-99.

9. Landier J, Akonde A, Pizzocolo C, Haidara I, Drabo M, et al. (2011) Switch to second-line ART in West African routine care: Incidence and reasons for switching. AIDS Care 23: 75-78.

10. Inzaule S, Otieno J, Kalyango J, Nafisa L, Kabugo C, et al. (2014) Incidence and predictors of first line antiretroviral regimen modification in western Kenya. PLoS ONE 9: e93106.

11. Abgrall S, Ingle SM, May MT, Costagliola D, Mercie P, et al. (2013) Durability of first ART regimen and risk factors for modification, interruption or death in HIV-positive patients starting ART in Europe and North America 2002-2009. AIDS 27: 803-813.

12. Jarrin I, Hernandez-Novoa B, Alejos B, Riera M, Navarro G, et al. (2013) Persistence of novel first-line antiretroviral regimes in a cohort of HIV-positive subjects, CoRIS 2008-2010. Antiviral therapy 18: 161-170.

13. Cicconi P, Cozzi-Lepri A, Castagna A, Trecarichi EM, Antinori A, et al. (2010) Insights into reasons for discontinuation according to year of starting first regimen of highly active antiretroviral therapy in a cohort of antiretroviral-naıve patients. HIV Medicine 11: 104-113.
14. Mihanović MP, Haque NS, Rutherford GW, Zekan S, Begovac J (2013) Toxicity-related antiretroviral drug treatment modifications in individuals starting therapy: A cohort analysis of time patterns, sex and other risk factors. Med Sci Monit 19: 483-492.

15. Sun J, Liu L, Shen J, Qi T, Wang Z, et al. (2015) Reasons and risk factors for the initial regimen modification in Chinese treatment-naïve patients with HIV infection: A retrospective cohort analysis. PLos ONE 10: e0133242.

16. De Beaudrap P, Etard JF, Guèye FN, Guèye M, Landman R, et al. (2008) Longterm efficacy and tolerance of efavirenz- and nevirapine-containing regimens in adult HIV type 1 Senegalese patients. AIDS Res Hum Retroviruses 24: 753-760.

17. Kiguba R, Byakika-Tusiime J, Karamagi C, Ssali F, Mugyenyi P, et al. (2007) Discontinuation and modification of highly active antiretroviral therapy in HIVinfected Ugandans: Prevalence and associated factors. J Acquir Immune Defic Syndr 45: 218-223.

18. Orrell C, Harling G, Lawn SD, Kaplan R, McNally M, et al. (2007) Conservation of first-line antiretroviral treatment regimen where therapeutic options are limited. Antivir Ther 12: 83-88.

19. Pujades-Rodríguez M, O'Brien D, Humblet P, Calmy A (2008) Second-line antiretroviral therapy in resource-limited settings: The experience of Médecins Sans Frontières. AIDS 22: 1305-1312.

20. Toure S, Kouadio B, Seyler C, Traore M, Dakoury-Dogbo N, et al. (2008) Rapid scaling-up of antiretroviral therapy in 10,000 adults in Côte d'Ivoire: 2-year outcomes and determinants. AIDS 22: 873-882.

21. Njuguna C, Orrell C, Kaplan R, Bekker LG, Wood R, et al. (2013) Rates of switching antiretroviral drugs in a primary care service in South Africa before and after introduction of tenofovir. PLoS ONE 8: e63596.

22. Prosperi MCF, Fabbiani M, Fanti L, Zaccarelli M, Colafigli M, et al. (2012) Predictors of first-line antiretroviral therapy discontinuation due to drug-related adverse events in HIV-infected patients: A retrospective cohort study. BMC Infect Dis 12: 296.

23. Chandy S, Singh G, Heylen E, Gandhi M, Ekstrand ML (2011) Treatment switching in south Indian patients on HAART: What are the predictors and consequences? AIDS Care 23: 569-577.

24. Sheth AN, Ofotokun I, Buchacz K, Armon C, Chmiel JS, et al. (2016) Antiretroviral regimen durability and success in treatment-naive and treatmentexperienced patients by year of treatment initiation, United States, 1996-2011. $\mathrm{J}$ Acquir Immune Defic Syndr 71: 47-56.

25. Slama L, Li X, Brown T, Jacobson LP, Pialoux G, et al. (2014) Increases in duration of first highly active antiretroviral therapy over time (1996-2009) and associated factors in the Multicenter AIDS Cohort Study. J Acquir Immune Defic Syndr 65: 57-64

26. Wright S, Boyd MA, Yunihastuti E, Law M, Sirisanthana T, et al. (2013) Rates and factors associated with major modifications to first-line combination antiretroviral therapy: Results from the Asia-Pacific region. PLoS ONE 8: e64902. 